\title{
Mutually exclusive recurrent KRAS and MAP2K1 mutations in Rosai-Dorfman disease
}

Sofia Garces ${ }^{1}$, L Jeffrey Medeiros ${ }^{1}$, Keyur $\mathrm{P} \mathrm{Patel}^{1}$, Shaoying Li ${ }^{1}$, Sergio Pina-Oviedo ${ }^{1}$, Jingyi Li ${ }^{1}$, Juan C Garces ${ }^{2}$, Joseph D Khoury ${ }^{1}$ and C Cameron Yin ${ }^{1}$

${ }^{1}$ Department of Hematopathology, The University of Texas MD Anderson Cancer Center, Houston, TX, USA and ${ }^{2}$ Instituto Oncológico Nacional Dr Juan Tanca Marengo, Guayaquil, Ecuador

\begin{abstract}
Rosai-Dorfman disease is a histiocytic disorder with a poorly defined pathogenesis. Recent molecular studies have revealed recurrent mutations involving genes in the MAPK/ERK pathway in Langerhans cell histiocytosis and Erdheim-Chester disease. However, cases of Rosai-Dorfman disease have rarely been assessed. We performed next-generation sequencing to assess 134 genes on 21 cases of Rosai-Dorfman disease, including 13 women and 8 men with a median age of 43 years (range, 3-82). In all, 13 had extranodal, 5 had nodal, and 3 had coexistent nodal and extranodal disease. The head and neck region was the most common area involved $(n=7)$. Mutation analysis detected point mutations in $7(33 \%)$ cases, including KRAS $(n=4)$ and MAP2K1 $(n=3)$. No mutations were identified in ARAF, BRAF, PIK3CA, or any other genes assessed. Immunohistochemistry demonstrated p-ERK overexpression in 3 cases, all harboring MAP2K1 mutations. Patients carrying mutated genes were younger (median age, 10 vs 53 years, $P=0.0347$ ) with more pediatric patients $(4 / 7$ vs $1 / 14, P=0.0251)$. The presence of mutations correlated with location being more common in the head and neck region; $6 / 7(86 \%)$ mutated vs $1 / 14(7 \%)$ unmutated cases $(P=0.0009)$. All $5(100 \%)$ mutated cases with available staging information had a multifocal presentation, whereas only $3 / 11(27 \%)$ unmutated patients had multifocal disease $(P=0.0256)$. Treatment information was available in 10 patients, including radical resection $(n=4)$, resection and radiation $(n=3)$, and cladribine-based chemotherapy $(n=3)$. With a median follow-up of 84 months (range, 7-352), 7 remained in clinical remission and 3 had persistent disease. No correlation between mutation status and clinical outcome was noted. In summary, we detected mutually exclusive KRAS and MAP2K1 mutations in one-third of cases of Rosai-Dorfman disease suggesting this subgroup are clonal and involve activation of MAPK/ERK pathway. Our data contribute to the understanding of the biology of Rosai-Dorfman disease and point to potential diagnostic and therapeutic targets.
\end{abstract}

Modern Pathology (2017) 30, 1367-1377; doi:10.1038/modpathol.2017.55; published online 30 June 2017

Rosai-Dorfman disease, also known as sinus histiocytosis with massive lymphadenopathy, is a rare nodal and/or extranodal histiocytic disorder characterized by the accumulation of abnormal histiocytes undergoing emperipolesis. The latter is defined as the active, non-destructive engulfment of leukocytes, lymphocytes, plasma cells, and erythrocytes by histiocytes, and is considered the histologic hallmark of Rosai-Dorfman disease. ${ }^{1,2}$ Initially described by Destombes ${ }^{3}$ and extensively characterized by Rosai and Dorfman, ${ }^{2,4-7}$ Rosai-Dorfman disease has been considered a non-neoplastic entity with

Correspondence: Dr CC Yin, MD, PhD, Department of Hematopathology, Unit 72, 1515 Holcombe Boulevard, Houston, TX 77030, USA.

E-mail: cyin@mdanderson.org

Received 16 February 2017; revised 13 April 2017; accepted 19

April 2017; published online 30 June 2017 unique histopathologic features that usually has a self-limited, albeit protracted, clinical course. Fatalities are uncommon reported to be in the range of 5$10 \%{ }^{4,5,8}$ Even though Rosai-Dorfman disease has been recognized for almost five decades, its etiology remains largely unknown. It has been hypothesized that Rosai-Dorfman disease may result from underlying host immune dysregulation, likely due to a precipitating event, such as a viral infection. However, published studies have resulted in conflicting data regarding the association of Rosai-Dorfman disease with Epstein-Barr virus, human herpesvirus-6, and parvovirus B19 infection. ${ }^{9-13}$ Other authors have highlighted a possible association between Rosai-Dorfman disease and IgG4-related disease as well as various autoimmune disorders. ${ }^{14,15}$ In addition, rare inherited conditions predisposing to RDD or RDD-like lesions have been recently described, namely $\mathrm{H}$ (Faisalabad) syndrome 
related to mutations in the nucleoside transporter gene SLC29A3, and autoimmune lymphoproliferative syndrome type Ia harboring germline mutations in the gene encoding Fas. ${ }^{15}$ However, mutations of these genes have not been reported in sporadic cases.

In the last decade, molecular studies on histiocytic disorders have shed light on the pathogenesis of these disorders. Mutually exclusive recurrent somatic mutations involving genes in the mitogenactivated protein kinase/extracellular signalregulated kinase (MAPK/ERK) pathway, including $B R A F$ V600E and MAP2K1 have been identified in about $50-70 \%$ of cases of Langerhans cell histiocytosis and Erdheim-Chester disease, leading to a better understanding of the biology of these diseases as well as recognition of potential therapeutic targets. ${ }^{16-21}$ More recently, abnormalities in other cellular pathways have been implicated in the pathogenesis of non-Langerhans cell histiocytosis cases. Mutations of PI3KCA in the PI3K-AKT-mTOR pathway, an alternative downstream effector of RAS signaling, have been shown in a subset of ErdheimChester disease cases. ${ }^{20-22}$ Furthermore, ERK activation has been found in a subset of $B R A F$ - and MAP2K1-wild-type Langerhans cell histiocytosis and non-Langerhans cell histiocytosis cases. ${ }^{21,23}$ These molecular discoveries have played an important role in the stratification of Langerhans cell histiocytosis and Erdheim-Chester disease from other histiocytoses in the recently revised classification of histiocytoses ${ }^{15}$ conversely a very limited number of Rosai-Dorfman disease cases have been investigated for gene mutations and the results have been controversial. In the largest genomic study to date, eight cases were analyzed by next-generation sequencing and mutations were detected involving KRAS, NRAS, and ARAF in two (25\%), one (12.5\%), and one $(12.5 \%)$ case, respectively. ${ }^{21}$

In this study we assessed 21 cases of RosaiDorfman disease for mutations of a panel of 134 genes that are commonly mutated in hematopoietic neoplasms. To our knowledge, this study represents the largest cohort of Rosai-Dorfman disease patients evaluated for recurrent genetic mutations. Our findings add important information regarding the pathogenesis and biology of Rosai-Dorfman disease and point to potentially actionable therapeutic targets.

\section{Materials and methods}

\section{Study Group}

The study group is composed of 21 cases of RosaiDorfman disease. A total of 16 cases with available paraffin blocks or unstained slides were culled from the archives of the Department of Hematopathology at The University of Texas MD Anderson Cancer Center from 1 January 2002 to 31 December 2015. In addition, paraffin blocks of 5 additional cases were obtained from the archives of the National Oncologic
Institute Dr Juan Tanca Marengo, Guayaquil, Ecuador. Available clinical and laboratory data were retrieved from the medical records. Routinely prepared hematoxylin-eosin-stained slides for all cases were reviewed. The study was conducted under an Institutional Review Board-approved protocol.

\section{Immunohistochemistry}

Immunohistochemical studies were performed in a subset of cases using antibodies specific for CD1a (Leica Biosystem, Newcastle, UK); CD3, CD20, CD68, and CD163 (DAKO, Carpinteria, CA, USA); S-100 protein (BioGenex, Fremont, CA, USA); and Ki-67 (DAKO). Specifically for this study, a highly specific antibody phospho-p44/42 MAPK (Thr202/Tyr204) (D13.14.4E) p-ERK (dilution 1:300, Cell Signaling, Danvers, MA, USA) was used to assess for the presence of nuclear and cytoplasmic phosphorylated p44 and p42 MAPK (Erk1 and Erk2).

\section{Next-generation Sequencing}

We performed amplicon-based next-generation sequencing targeting the coding regions of a panel of 134 genes that are commonly mutated in hematopoietic neoplasms using the Ion Torrent platform (Thermo Fisher Scientific, Waltham, MA, USA) on DNA extracted from paraffin-embedded tissues as described previously. ${ }^{24,25}$ For three cases we were able to retrieve tissues that were not involved by Rosai-Dorfman disease to be used as a control. We used $20 \mathrm{ng}$ of DNA to prepare the genomic library. The genes included in the panel are as follows: $A B L 1$; ACVRL1; AKT1; ALK; APC; APEX1; AR; ARAF; ATM; ATP11B; BAP1; BCL2L1; BCL9; BIRC2; BIRC3; BRAF; BRCA1; BRCA2; BTK; CBL; CCND1; CCNE1; CD274; CD44; CDH1; CDK4; CDK6; CDKN2A; CHEK2; CSF1R; CSNK2A1; CTNNB1; DCUN1D1; DDR2; DNMT3A; EGFR; ERBB2; ERBB3; ERBB4; ESR1; EZH2; FBXW7; FGFR1; FGFR2; FGFR3; FGFR4; FLT3; FOXL2; GAS6; GATA2; GATA3; GNA11; GNAQ; GNAS; HNF1A; HRAS; IDH1; IDH2; IFITM1; IFITM3; IGF1R; IL6; JAK1; JAK2; JAK3; KDR; KIT; KNSTRN; KRAS; MAGOH; MAP2K1; MAP2K2; MAPK1; MAX; MCL1; MDM2; MDM4; MED12; MET; MLH1; MPL; MSH2; MTOR; MYC; MYCL; MYCN; MYD88; MYO18A; NF1; NF2; NFE2L2; NKX2-1; NKX2-8; NOTCH1; NPM1; NRAS; PAX5; PDCDILG2; PDGFRA; PIK3CA; PIK3R1; PNP; PPARG; PPP2R1A; PTCH1; PTEN; PTPN11; RAC1; RAF1; RB1; RET; RHEB; RHOA; RPS6KB1; SF3B1; SMAD4; SMARCB1; SMO; SOX2; SPOP; SRC; STAT3; STK11; TERT; TET2; TIAF1; TP53; TSC1; TSC2; U2AF1; VHL; WT1; XOP1; and ZNF217. Following successful library generation and purification, DNA was used for multiplex sequencing and analyzed using the Torrent Suite and OncoSeek data pipeline. 


\section{Statistical Analysis}

Correlation between mutation status and clinicopathologic features including age, gender, anatomic site, stage, and clinical outcome were assessed using Fisher's exact test. Age at diagnosis was compared between the two groups using Student $t$-test. All $P$ values were two-sided and considered statistically significant if $<0.05$.

\section{Results}

\section{Clinical Features, Laboratory Findings, and Outcome}

The study group included 21 patients, 13 women and 8 men with a median age of 43 years (range, 382). There were 16 adults and 5 pediatric patients (age range, 3-10 years). The clinical and laboratory features at diagnosis are summarized in Table 1. In all, 13 patients had only extranodal disease, 5 had nodal disease alone, and 3 had coexistent nodal and extranodal disease. Overall, the head and neck region was the most common region involved $(n=7)$. The most common extranodal site was soft tissue $(n=7)$, followed by nasal cavity $(n=4)$, breast $(n=3)$, orbit $(n=2)$, and lung $(n=1)$. A total of 5 patients had osteolytic lesions, including 4 in the nasal septum and 1 involving the ulna; 3 patients with osteolytic lesions in the nasal septum had extension into the base of skull. In 1 patient the disease was found incidentally in the soft tissue surrounding a mesenteric lymph node dissected for prostate adenocarcinoma staging. None of the 10 patients with available information had a history of autoimmune disease, immunodeficiency, or signs or symptoms of other inherited conditions, including those associated with Rosai-Dorfman disease, such as $\mathrm{H}$ (Faisalabad) syndrome or autoimmune lymphoproliferative syndrome type Ia.

Two of $13(15 \%)$ patients presented with B-symptoms; both had exclusively nodal involvement. All patients with nasal lesions had epistaxis at initial presentation and 3 presented with nasal polyps. Two patients with orbital lesions had visual disturbances, including proptosis and temporary vision loss. Lymphadenopathy was present in 11 of 16 (69\%) patients, whereas hepatosplenomegaly was present in 1 of 11 (9\%) patients with available information. Clinical staging data were available for 16 patients; disease was unifocal in 8 and multifocal in 8 .

Complete blood cell counts were available in 10 patients. Two patients presented with mild leukocytosis and 2 presented with mild leukopenia (median white blood cell count, $7.2 \times 10^{3} / \mu \mathrm{l}$; range, 2.4-18.3 $\times 10^{3} / \mu \mathrm{l}$; reference range, $\left.4-11 \times 10^{3} / \mu \mathrm{l}\right)$, 6 patients had mild normocytic anemia (median hemoglobin, $12.3 \mathrm{~g} / \mathrm{dl}$; range, $11.5-15.8 \mathrm{~g} / \mathrm{dl}$; reference range, 14-18 g/dl for men and 12-16 g/dl for women), and 1 patient had thrombocytopenia (median platelet count, $278 \times 10^{3} / \mu \mathrm{l}$; range, $74-352 \times 10^{3} / \mu \mathrm{l}$; reference range, $\left.140-440 \times 10^{3} / \mu \mathrm{l}\right)$. Serum lactate dehydrogenase was within normal limits in 9 patients (median, $403 \mathrm{IU} / \mathrm{l}$; range, 333-591 IU/l; reference range, 313-618 IU/l) and $\beta 2$-microglobulin level was slightly elevated in 2 of 4 patients with available data (median, $2 \mathrm{mg} / \mathrm{l}$; range, $1.6-2.4 \mathrm{mg} / \mathrm{l}$; reference range, $0.7-1.8 \mathrm{mg} / \mathrm{l})$.

Clinical follow-up data were available for 10 patients. These patients were treated with different protocols that included surgical excision alone $(n=4)$, surgical excision combined with radiation therapy $(n=3)$, and cladribine-based chemotherapy combined with excision and/or radiation $(n=3)$. With a median follow-up of 84 months (range, 7-352), 7 patients were in clinical remission and 3 patients had persistent disease at last follow-up. All patients remained alive at the end of the study period.

\section{Histologic Features}

Irrespective of the location, all cases had variable numbers of the characteristic abnormal histiocytes with a round or oval nucleus, a distinct central nucleolus, and abundant clear to eosinophilic cytoplasm that was occasionally vacuolated or finely granular (Figures 1-3). In every case there was emperipolesis in a subset of the histiocytes (Figures 1-3), although emperipolesis was much less obvious in extranodal sites, particularly when associated with dense fibrosis (Figure 1b). Involved lymph nodes were enlarged with a variably thickened, fibrotic capsule, and nodal architecture was partially distorted by expanded sinuses that contained many characteristic histiocytes, lymphocytes, plasma cells and occasional erythrocytes, eosinophils, and neutrophils (Figure 2). At extranodal sites the predominant feature was an infiltrate of abnormal histiocytes, in small or large aggregates, associated with a dense lymphoplasmacytic infiltrate embedded in a fibrotic and/or edematous background (Figures 1 and 3). Multinucleated histiocytes were observed in 5 (24\%) cases; however, granuloma formation was present focally in only in 1 (5\%) case. Two $(9.5 \%)$ cases showed rare, scattered Touton giant cells. One (5\%) case showed a minute focus of necrosis. No mitotic figures were identified in the histiocytic infiltrate in any of the 21 cases examined.

\section{Targeted Next-generation Sequencing Results}

A total of 134 genes were analyzed by next-generation sequencing. Mutations were detected in 7 of 21 (33\%) cases, including $K R A S(n=4)$ and MAP2K1 $(n=3)$, and the mutations were point mutations in all 7 cases. Among the KRAS-mutated cases, 2 cases had mutations in exon 2 (c.35G $>$ A p.G12D and c.64C $>$ A p.Q22K) and 2 had mutations in exon 4 (c.351A $>$ T p.K117N and c.436G $>$ A p.A146T). The median allelic frequency of $K R A S$ mutation was $4.69 \%$ (range, 3.53-5.64\%). Among the MAP2K1-mutated cases, 2 cases had mutations in exon 3 (c.371C $>$ G p.P124R and c.383G $>$ A p.G128D) and 1 had a mutation in 
Table 1 Clinical features, laboratory findings including next-generation sequencing results, and outcome of patients with Rosai-Dorfman disease

\begin{tabular}{|c|c|c|c|c|c|c|c|c|c|c|c|c|c|c|c|c|c|c|}
\hline Patient no. & $\begin{array}{c}\text { Age } \\
\text { (years) }\end{array}$ & Sex & B-symptoms & $L A D$ & $H S M$ & Nodal & Extranodal & Stage & $\begin{array}{l}W B C \\
\left(\times 10^{9} / 1\right)\end{array}$ & $\begin{array}{l}H G B \\
(g / d l)\end{array}$ & $\begin{array}{l}P L T \\
(K / \mu l)\end{array}$ & $\begin{array}{l}L D H \\
(I U / I)\end{array}$ & $\begin{array}{l}B 2 M \\
(m g / l)\end{array}$ & $\begin{array}{l}\text { Mutations } \\
\text { detected by } \\
\text { NGS }\end{array}$ & $\begin{array}{l}p- \\
E R K \\
I H C\end{array}$ & Therapy & $F U(\mathrm{~m})$ & Outcome \\
\hline 1 & 4 & $\mathrm{~F}$ & No & Yes & No & Cervical & Orbital & Multifocal & 7.5 & 12.1 & 380 & 591 & NA & $\begin{array}{l}\text { KRAS } \\
\text { c.351 A>T p. } \\
\text { K117N }\end{array}$ & $\mathrm{N}$ & $\begin{array}{l}\text { Multiple } \\
\text { including } \\
\text { cladribine }\end{array}$ & 141 & CR \\
\hline 2 & 32 & $\mathrm{~F}$ & No & No & No & No & $\begin{array}{l}\text { Soft tissue of } \\
\text { trunk }\end{array}$ & Unifocal & 6 & 12.7 & 257 & 333 & 1.6 & None & $\mathrm{N}$ & $\begin{array}{l}\text { Resection, } \\
\text { radiation }\end{array}$ & 142 & CR \\
\hline 3 & 34 & $\mathrm{~F}$ & NA & NA & NA & No & $\begin{array}{l}\text { Soft tissue of } \\
\text { trunk }\end{array}$ & NA & NA & NA & NA & NA & NA & $\begin{array}{l}\text { KRAS } \\
\text { c.64C >A p. } \\
\text { Q22K }\end{array}$ & $\mathrm{N}$ & NA & NA & NA \\
\hline 4 & 7 & $\mathrm{~F}$ & No & Yes & No & $\begin{array}{l}\text { Multi- } \\
\text { compartment }\end{array}$ & $\begin{array}{l}\text { Paranasal } \\
\text { sinuses, lung, } \\
\text { bone }\end{array}$ & Multifocal & 5.6 & 11.5 & 352 & 403 & 1.9 & $\begin{array}{l}\text { MAP2K1, } \\
\text { c.371C }>\text { G p. } \\
\text { P124R } \\
\text { CDH1, } \\
\text { c.211C }>\text { T p. } \\
\text { L71F }\end{array}$ & $\mathrm{P}$ & $\begin{array}{l}\text { Multiple } \\
\text { including } \\
\text { radiation and } \\
\text { cladribine }\end{array}$ & 352 & CR \\
\hline $\begin{array}{l}5 \\
6\end{array}$ & $\begin{array}{l}21 \\
82\end{array}$ & $\begin{array}{l}\mathrm{F} \\
\mathrm{M}\end{array}$ & $\begin{array}{l}\text { No } \\
\text { Yes }\end{array}$ & $\begin{array}{l}\text { No } \\
\text { Yes }\end{array}$ & $\begin{array}{l}\text { No } \\
\text { Yes }\end{array}$ & $\begin{array}{l}\text { No } \\
\text { Inguinal }\end{array}$ & $\begin{array}{l}\text { Breast } \\
\text { No }\end{array}$ & $\begin{array}{l}\text { Unifocal } \\
\text { Unifocal }\end{array}$ & $\begin{array}{l}3.8 \\
\text { NA }\end{array}$ & $\begin{array}{l}11.9 \\
\mathrm{NA}\end{array}$ & $\begin{array}{l}287 \\
\text { NA }\end{array}$ & $\begin{array}{l}388 \\
\text { NA }\end{array}$ & $\begin{array}{l}\text { NA } \\
\text { NA }\end{array}$ & $\begin{array}{l}\text { None } \\
\text { None }\end{array}$ & $\begin{array}{l}\mathrm{N} \\
\mathrm{NA}\end{array}$ & $\begin{array}{l}\text { Resection } \\
\text { NA }\end{array}$ & $\begin{array}{l}16 \\
\text { NA }\end{array}$ & $\begin{array}{l}\text { PD } \\
\text { NA }\end{array}$ \\
\hline 7 & 53 & $\mathrm{M}$ & No & No & No & No & $\begin{array}{l}\text { Base of skull, } \\
\text { orbital }\end{array}$ & Multifocal & 7.1 & 15.8 & 250 & 424 & NA & $\begin{array}{l}\text { KRAS } 35 G>A \\
\text { p.G12D }\end{array}$ & $\mathrm{N}$ & Resection & 7 & CR \\
\hline 8 & 68 & M & No & Yes & No & No & $\begin{array}{l}\text { Extranodal soft } \\
\text { tissue }^{\mathrm{b}}\end{array}$ & Unifocal & 18.3 & 12.5 & 283 & 398 & NA & None & $\mathrm{N}$ & Resection & 54 & CR \\
\hline 9 & 53 & $\mathrm{~F}$ & NA & NA & NA & No & Breast & NA & NA & NA & NA & NA & NA & None & NA & NA & NA & NA \\
\hline 10 & 64 & M & No & No & No & No & $\begin{array}{l}\text { Bone of upper } \\
\text { extremity, } \\
\text { nasopharynx, } \\
\text { paranasal sinuses }\end{array}$ & Multifocal & 7.3 & 13.9 & 185 & 443 & 2.4 & None & $\mathrm{N}$ & $\begin{array}{l}\text { Multiple } \\
\text { including } \\
\text { resection, } \\
\text { radiation \& } \\
\text { cladribine }\end{array}$ & 94 & PD \\
\hline 11 & 3 & M & NA & Yes & NA & Cervical & No & NA & NA & NA & NA & NA & NA & $\begin{array}{l}\text { MAP2K1 } \\
\text { c.157 T >G p. } \\
\text { F53V }\end{array}$ & $\mathrm{P}$ & NA & NA & NA \\
\hline 12 & 64 & M & No & Yes & NA & $\begin{array}{l}\text { Multi- } \\
\text { compartment }\end{array}$ & Nasopharynx & Multifocal & 2.4 & 11.9 & 74 & 372 & NA & $\begin{array}{l}\text { MAP2K1 } \\
\text { c.383G }>\text { A p. } \\
\text { G128D }\end{array}$ & $\mathrm{P}$ & $\begin{array}{l}\text { Resection, } \\
\text { radiation, } \\
\text { Cladribine }\end{array}$ & 74 & PD \\
\hline 13 & 10 & $\mathrm{~F}$ & No & Yes & No & No & $\begin{array}{l}\text { Base of skull, } \\
\text { adenoids, } \\
\text { nasopharynx }\end{array}$ & Multifocal & 16.3 & 15.1 & 272 & NA & NA & $\begin{array}{l}\text { KRAS } \\
\text { c. } 436 \mathrm{G}>\mathrm{A} \mathrm{p} . \\
\text { A146T }\end{array}$ & $\mathrm{N}$ & Resection & 26 & CR \\
\hline 14 & 35 & $\mathrm{~F}$ & No & Yes & No & No & $\begin{array}{l}\text { Soft tissue of } \\
\text { lower extremity }\end{array}$ & Multifocal & NA & NA & NA & NA & NA & None & $\mathrm{N}$ & NA & NA & NA \\
\hline 15 & 61 & $\mathrm{~F}$ & NA & NA & NA & No & $\begin{array}{l}\text { Soft tissue of } \\
\text { trunk }\end{array}$ & NA & NA & NA & NA & NA & NA & None & $\mathrm{N}$ & NA & NA & NA \\
\hline 16 & 53 & $\mathrm{~F}$ & No & No & No & No & Breast & Unifocal & 9 & 11.6 & 288 & 520 & 2 & None & $\mathrm{N}$ & Resection & 154 & CR \\
\hline 17 & 43 & $\mathrm{~F}$ & NA & NA & NA & No & $\begin{array}{l}\text { Soft tissue of } \\
\text { trunk }\end{array}$ & Unifocal & NA & NA & NA & NA & NA & None & $\mathrm{N}$ & NA & NA & NA \\
\hline 18 & 36 & $\mathrm{M}$ & NA & NA & NA & No & $\begin{array}{l}\text { Soft tissue of } \\
\text { upper extremity }\end{array}$ & NA & NA & NA & NA & NA & NA & None & $\mathrm{N}$ & NA & NA & NA \\
\hline 19 & 4 & $\mathrm{~F}$ & Yes & Yes & NA & $\begin{array}{l}\text { Multi- } \\
\text { compartment }\end{array}$ & No & Multifocal & NA & NA & NA & NA & NA & None & $\mathrm{N}$ & NA & NA & NA \\
\hline 20 & 63 & $\mathrm{~F}$ & NA & Yes & NA & Cervical & No & Unifocal & NA & NA & NA & NA & NA & None & $\mathrm{N}$ & NA & NA & NA \\
\hline 21 & 72 & $\mathrm{M}$ & NA & Yes & NA & Cervical & No & Unifocal & NA & NA & NA & NA & NA & None & $\mathrm{N}$ & NA & NA & NA \\
\hline
\end{tabular}

B2M, beta-2-microglobulin; CR, complete remission; F, female; FU, follow-up; HGB, hemoglobin; HSM, hepatosplenomegaly; IHC, immunohistochemistry; LAD, lymphadenopathy; LDH, lactate dehydrogenase; m, months; M, male; N, negative; NA, not available; NGS, next-generation sequencing; P, positive; PD, persistent disease; PLT, platelets; WBC, white blood cells. Age indicates age at initial diagnosis.

${ }^{\mathrm{b}}$ Incidental finding in the soft tissue surrounding a mesenteric lymph node removed for staging of prostatic carcinoma. 
exon 2 (c.157 T $>$ G p.F53V). The median allelic frequency of $M A P 2 K 1$ mutation was $4.99 \%$ (range, 4.49-7.62\%). KRAS and MAP2K1 mutations did not coexist in any cases. An additional novel somatic mutation in $C D H 1$ (c. $211 \mathrm{C}>\mathrm{T}$ p.L71F) with an allelic frequency of $8.75 \%$ was identified in a $M A P 2 K_{1}$ mutated case (case 4).

The patients harboring mutations were four women and three men with a median age of 10 (range, 3-64); four (57\%) patients were children. Three (43\%) had exclusively extranodal disease, three $(43 \%)$ had concomitant nodal and extranodal disease, and one (14\%) had only nodal disease. Six of seven $(86 \%)$ cases with mutations were from the head and neck region, specifically nasal cavity $(n=3)$, orbit $(n=2)$, cervical lymph node $(n=1)$, and soft tissue of trunk $(n=1)$. All five patients with mutations with available staging information had a multifocal disease presentation. Of five patients with available follow-up information, with a median follow-up of 74 months (range, 7-352), four $(80 \%)$ showed clinical remission and one $(20 \%)$ had persistent disease. Among the group that experienced clinical remission, two underwent surgical excision alone and two received multiple therapeutic regimens, including cladribine-based therapy.

No mutations in 134 genes assessed were detected in $14(67 \%)$ patients, which included 9 women and 5 men. The median age was 53 (range, 4-82) and included only $1(7 \%)$ pediatric patient. Unmutated lesions were exclusively extranodal in 10 patients and exclusively nodal in 4 patients. The locations of the extranodal lesions included soft tissue of the trunk and extremity or surrounding a lymph node $(n=6)$, breast $(n=3)$, and nasal cavity $(n=1)$, and the lymph node regions involved were cervical $(n=2)$, inguinal $(n=1)$, and multicompartmental $(n=1)$. In 1 (7\%) patient the lesion was located in the head and neck region. For 11 patients with available staging data, 8 (73\%) had unifocal and $3(27 \%)$ had multifocal disease. Of the 5 patients with available clinical information, with a median follow-up of 94 months (range, 16-154), 3 (60\%) were in clinical remission after surgical resection with $(n=1)$ or without $(n=2)$ radiation therapy, and $2(40 \%)$ had persistent disease in spite of surgical resection $(n=1)$ or cladribinebased therapy $(n=1)$.

Statistical analysis showed that patients with mutated genes were younger than those without mutations (median age, 10 vs 53 years, $P=0.0347$ ) with more pediatric patients in the mutated group (4/7 vs 1/14, $P=0.0251)$. Mutated cases also more commonly involved the head and neck region than unmutated cases (6/7 vs 1/14, $P=0.0009)$. All 5 $(100 \%)$ patients in the mutated group with available staging information had multifocal disease, whereas only $3 / 11(27 \%)$ patients in the unmutated group had multifocal disease $(P=0.0256$; Table 2$)$.

No definite morphologic differences were observed between mutated and unmutated cases. In addition to the typical histiocytic infiltrate that were seen in all cases, 2 of 7 (28\%) mutated (cases 1 and 11 ) and 3 of 14 (21\%) unmutated (cases 2, 5, and 15) cases showed occasional, scattered multinucleated histiocytes. One (14\%) mutated (case 11) and 1 (7\%) unmutated case (case 5) showed rare Touton giant cells; the latter case also showed focal granuloma formation. In addition, one unmutated case (case 15) showed a minute focus of necrosis.

\section{Immunohistochemistry}

Immunohistochemical studies showed that the histiocytes were strongly positive for S-100 protein in all cases, which facilitated the identification of emperipolesis. The histiocytes were positive for CD68 $(n=6)$ and CD163 $(n=5)$, and were negative for CD1a $(n=19)$, CD3 $(n=9)$, and CD20 $(n=9)$ in all cases assessed.

Immunohistochemical stains using Ki-67 antibody were performed in 16 cases, including 6 mutated and 10 unmutated cases. All cases showed a proliferation index of $<10 \%$. There was no difference between mutated and unmutated cases.

Immunohistochemical analysis using p-ERK antibody in 19 cases demonstrated high levels of expression in the nucleus and cytoplasm of the histiocytes in 3 cases (cases 4, 11, and 12), all harboring $M A P 2 K 1$ mutations. Conversely, none of the 4 patients with KRAS mutations (cases 1, 3, 7, and 13) or in whom no mutations were detected $(n=12)$ showed expression of p-ERK. In all cases, stromal cells, fibroblasts, and endothelial cells were positive for p-ERK (internal controls).

\section{Discussion}

The MAPK/ERK signaling pathway is a key regulatory pathway involved in many essential cellular processes, including cell proliferation, differentiation, apoptosis, and survival through a wide variety of nuclear, cytoplasmic, and cell membrane targets. $^{26}$ In a simplified unidirectional model, activation of the G-protein RAS triggers sequential changes in the phosphorylation status of the downstream kinases RAF and MEK, and the serine/ threonine kinases ERK-1 and $-2 .{ }^{27}$ Phosphorylated and activated ERK translocates to the nucleus where it regulates the activity of several transcription factors, which in turn induce expression of genes required for survival and proliferation. ${ }^{27,28}$ It is now well established that mutations that constitutively activate members of this pathway occur in several non-hematologic malignancies, including melanoma, gliomas, and carcinomas of the thyroid gland, lung, colon, ovary, and hepatobiliary system, ${ }^{29-31}$ as well as hematologic diseases, namely hairy cell leukemia, chronic myelomonocytic leukemia, Langerhans cell histiocytosis, and Erdheim-Chester disease. ${ }^{15,32-35}$ In the last decade, the discovery of $B R A F$ V600E mutation in Langerhans cell 

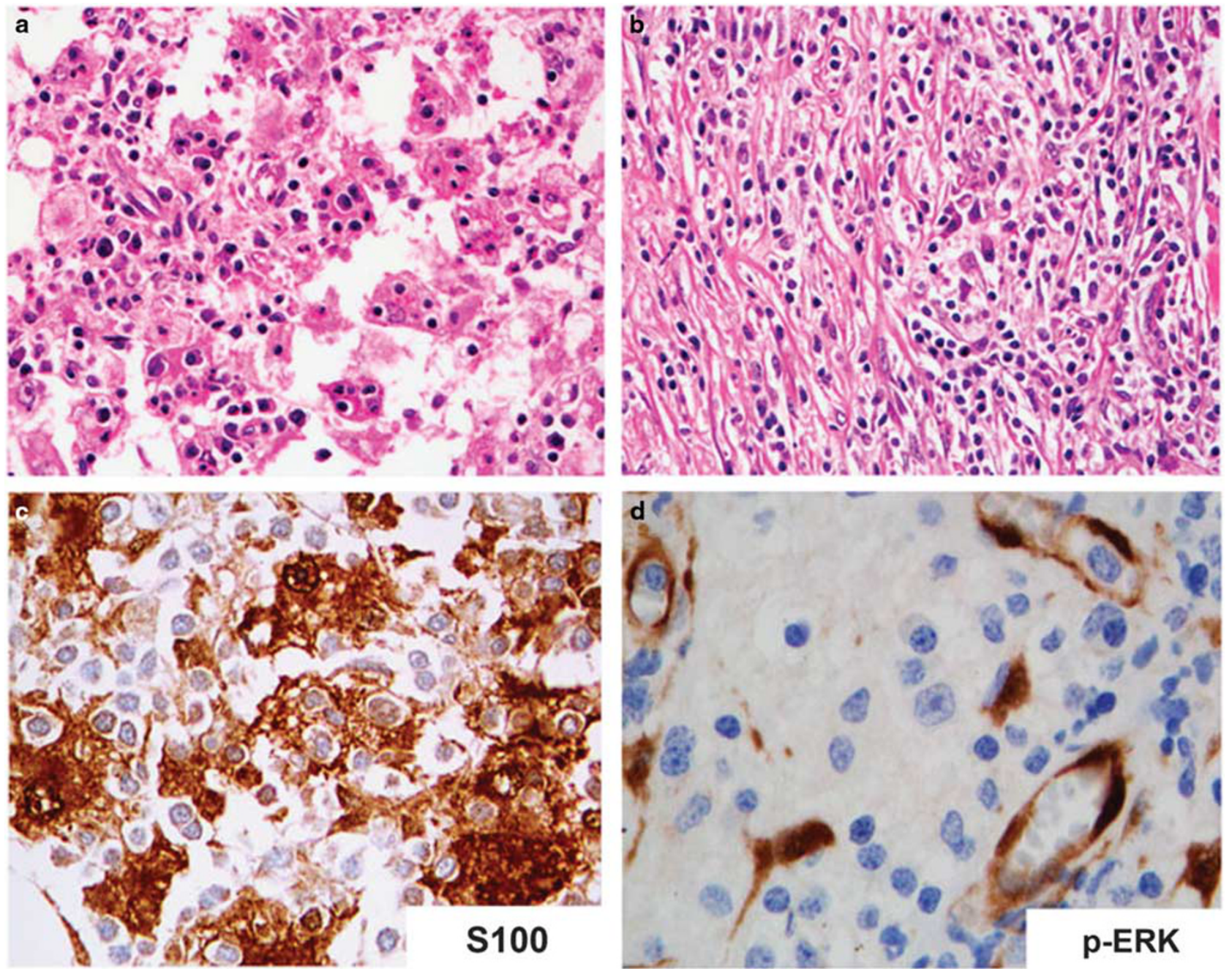

Figure 1 KRAS-mutated Rosai-Dorfman disease, soft tissue of trunk (case 3). (a) Medium-power image of soft tissue with aggregates of abnormal emperipoletic histiocytes $(\times 200)$. (b) Some areas show dense fibrosis where emperipoletic histiocytes are less obvious to identify $(\times 400)$. (c) Immunostain for S-100 is positive in Rosai-Dorfman histiocytes and negative in engulfed lymphocytes ( $\times 400)$. (d) Immunostain for p-ERK is negative in emperipoletic histiocytes (endothelial cells are positive; $\times 1000$ ).

histiocytosis and Erdheim-Chester disease, followed by MAP2K1 mutations in $B R A F$-wild-type Langerhans cell histiocytosis, significantly unraveled the underlying biology of these disorders. As the best example, the identification of BRAF V00E in subsets of circulating $\mathrm{CD} 11 \mathrm{c}^{+}$dendritic cells, $\mathrm{CD} 14^{+}$monocytes, and in bone marrow $\mathrm{CD} 34^{+}$hematopoietic cell progenitors in patients with high-risk Langerhans cell histiocytosis supports the pathogenic model in which Langerhans cell histiocytosis is a myeloidrelated neoplasm. ${ }^{36}$ Recently, Diamond et al. ${ }^{21}$ interrogated 37 patients with BRAF V600E-wildtype non-Langerhans cell histiocytosis histiocytoses by whole-exome sequencing and/or RNA sequencing, and demonstrated recurrent activating mutations in MAP2K1 (32\%), NRAS (16\%), KRAS (11\%), PIK3CA (8\%), and ARAF (3\%) in all types of nonLangerhans cell histiocytosis histiocytoses, including 8 patients with Rosai-Dorfman disease where $50 \%$ harbored mutually exclusive mutations involving KRAS, NRAS, or ARAF. ${ }^{21}$ Another recent single case report identified a KRAS K117N point mutation in a case of Rosai-Dorfman disease. ${ }^{37}$ In light of these breakthroughs, we hypothesized that activating mutations in the RAS/RAF/MAPK/ERK or related signaling pathways may have a key role in the pathogenesis of Rosai-Dorfman disease.

To answer this question, and further recognize the incidence of mutations in Rosai-Dorfman disease, we interrogated 21 cases of Rosai-Dorfman disease using next-generation sequencing for mutations in a panel of 134 genes. We identified mutually exclusive KRAS and MAP2K1 point mutations in one-third of the cases. In addition, a novel somatic mutation in the cadherin 1 (CDH11 L71F) gene was identified in one MAP2K1-mutated case; although the biologic and clinical significance of this finding is unclear. The remaining $67 \%$ of cases demonstrated wild-type status at all gene loci examined, including $A R A F$, BRAF, ERBB1, ERBB2, ERBB3, MAP2K1, NRAS, 

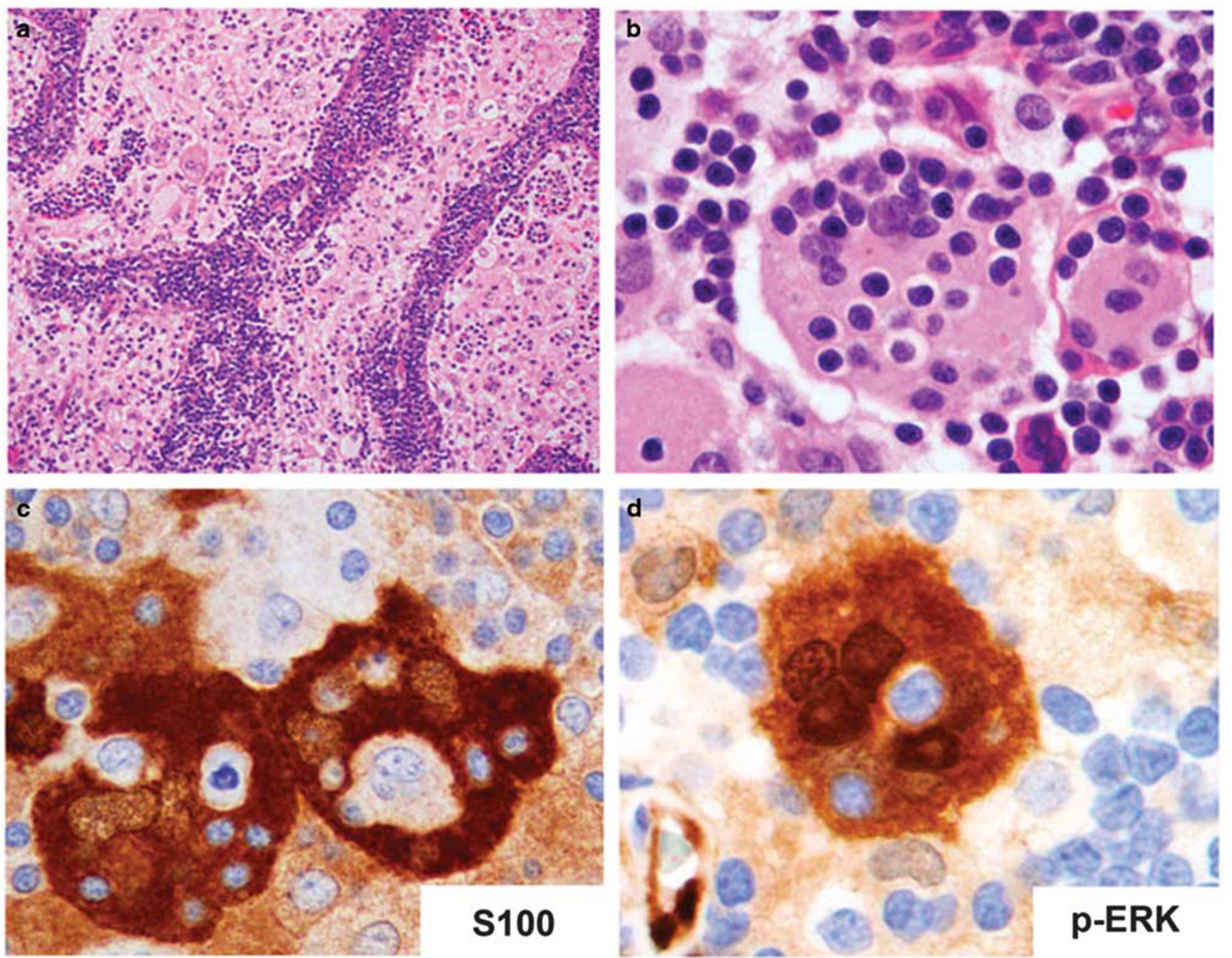

Figure 2 MAP2K1-mutated Rosai-Dorfman disease, nodal (case 11). (a) Low-power image of a lymph node with markedly expanded sinuses by numerous emperipoletic histiocytes, lymphocytes, and plasma cells $(\times 100)$. (b) High-power magnification of a distended sinus with a histiocyte engulfing numerous lymphocytes (×1000). (c) Immunostain for S-100 highlights Rosai-Dorfman histiocytes and provides contrast with numerous negatively outlined lymphocytes $(\times 1000)$. (d) Immunostain for p-ERK is positive in histiocytes in a nuclear and cytoplasmic pattern $(\times 1000)$.

PIK3CA, and PTEN. None of our cases had a BRAF mutation, confirming data from several prior studies that showed universal $B R A F$-wild-type status in Rosai-Dorfman disease. ${ }^{16,17,38,39}$ Of note, no mutations were identified in ARAF, NRAS, PIK3CA, or PTEN, unlike the results reported previously by Diamond et al. ${ }^{21}$ and another group. ${ }^{40}$ Our panel did not include $S L C 29 A 3$ or FAS genes; ${ }^{15}$ however, as previously mentioned none of the patients in our study cohort showed clinical characteristics of the inherited disorders associated with mutations in those genes. Whereas our sample size is the largest published to date, it is still limited, which precludes us from drawing any statistically significant conclusion on the effect of mutation status on clinical outcome. However, this small study group shows that patients harboring KRAS or MAP2K1 mutation have a lower median age with a higher occurrence in children, a higher frequency of involvement of the head and neck region, and a higher rate of multifocal disease. No correlation between mutation status and clinical outcome was noted. Furthermore, no differences in morphologic features or median Ki-67 proliferation index were observed between mutated and unmutated cases. A larger patient series is needed to confirm these preliminary associations.

We additionally showed p-ERK overexpression by immunohistochemistry in all MAP2K1-mutated cases supporting MAPK/ERK pathway activation, in keeping with activating mutations of this pathway. Interestingly, none of the patients with KRAS mutations or patients in whom no mutation was detected showed expression of p-ERK. We speculate that mutations of upstream signaling protein genes in the MAPK/ERK pathway, such as KRAS, may not cause downstream cascade activation to the same extent as $M A P 2 K 1$ alterations. The other possibility is that ERK activation is not a universal end point in 

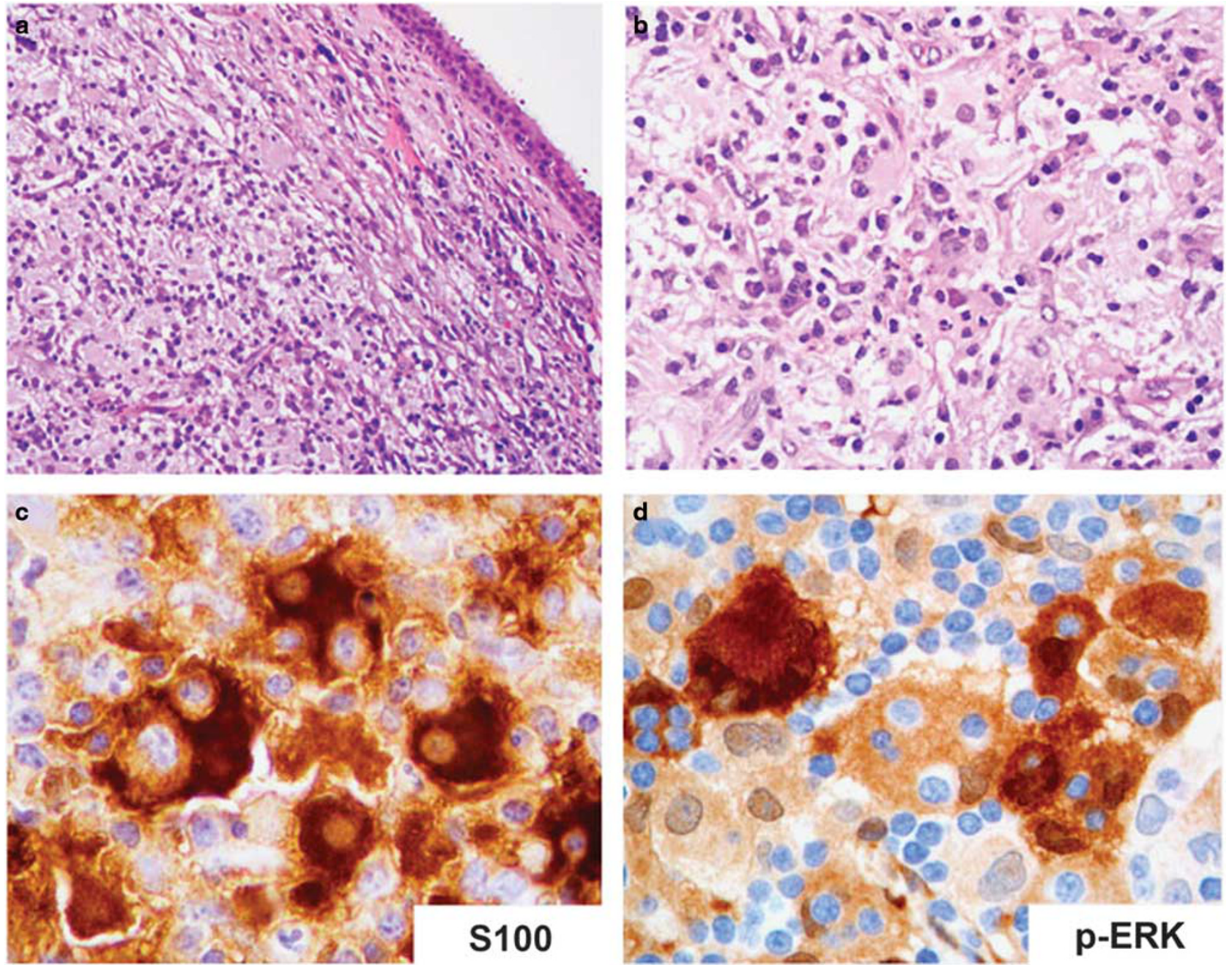

Figure 3 MAP2K1-mutated Rosai-Dorfman disease, nasopharynx (case 12). (a) Medium-power image of nasopharynx with sheets of histiocytes admixed with lymphocytes and plasma cells $(\times 200)$. (b) Higher magnification shows numerous histiocytes engulfing lymphocytes, plasma cells, and neutrophils $(\times 400)$. (c) Immunostain for S-100 is positive in histiocytes and negative in engulfed lymphocytes $(\times 400)$. (d) Immunostain for p-ERK is positive in the nucleus and cytoplasm of a subset of Rosai-Dorman histiocytes $(\times 500)$.

Rosai-Dorfman disease and that a proportion of cases utilize alternative pathways downstream of RAS or outside the MAPK/ERK pathway axis. Other authors have evaluated p-ERK expression by immunohistochemistry in non-Rosai-Dorfman disease histiocytoses. For instance, in a study that included 97 patients with Langerhans cell histiocytosis, Zeng et al. ${ }^{41}$ demonstrated a statistically significant correlation between the presence of BRAF or MAP2K1 mutations and p-ERK overexpression; interestingly in their cohort, expression of p-ERK was also observed in $40 \%$ of BRAF/MAP2K1-wild-type cases. Others observed that phosphorylation of downstream pathway mediators, such as ERK, can occur independently from mutations in $B R A F$ or $M A P 2 K 1$ in Langerhans cell histiocytosis or BRAF or NRAS in Erdheim-Chester disease. ${ }^{16,19,25}$ These findings suggested the existence of other mechanisms of perturbation of this kinase cascade. This idea was supported by a more recent study focused on Erdheim-Chester disease by Emile et al. In addition to BRAF V600E mutation present in more than half of the patients, NRAS and PIK3CA mutations were present in $10 \%$ and $3.7 \%$ of cases, respectively. Interestingly, $B R A F$ V600E and NRAS mutations, both being members of the MAPK/ERK pathway, appeared to be mutually exclusive; while PIK3CA mutation coexisted with $B R A F$ mutation in 4 of 7 cases, supporting involvement of both the PI3K/AKT and MAPK/ERK signaling pathways in a subset of Erdheim-Chester disease patients. ${ }^{20}$ In another recent study using wholeexome sequencing, targeted BRAF sequencing, and/or whole-transcriptome sequencing (RNA seq), alternative genetic mechanisms of ERK activation were identified in a subset of BRAF V600E-unmutated Langerhans cell histiocytosis, namely in-frame $B R A F$ deletions in the $\beta 3-\alpha \mathrm{C}$ loop and a FAM73A$B R A F$ fusion. ${ }^{23}$ Similarly, in non-Langerhans cell histiocytosis histiocytoses, MAPK-pathway-activating RNF11-BRAF, CLIP2-BRAF, KIF5B-ALK, and 
Table 2 Comparison of clinicopathologic features of patients with or without KRAS and MAP2K1 mutations

\begin{tabular}{|c|c|c|c|c|}
\hline & Total & KRAS or MAP2K1-mutated & Unmutated & $\mathrm{P}$-value \\
\hline Number & 21 & $7(33 \%)$ & $14(67 \%)$ & \\
\hline Age $(\text { years) })^{a}$ & $43(3-82)$ & $10(3-64)$ & $53(4-82)$ & 0.0347 \\
\hline No. of pediatric patients & $5(24 \%)$ & $4(57 \%)$ & $1(7 \%)$ & 0.0251 \\
\hline Gender & & & & 1.0000 \\
\hline Male & $8(38 \%)$ & $3(43 \%)$ & $5(36 \%)$ & \\
\hline Female & $13(62 \%)$ & $4(57 \%)$ & $9(64 \%)$ & \\
\hline \multicolumn{5}{|l|}{ Location, n (\%) } \\
\hline Head and neck & $7(33 \%)$ & $6(86 \%)$ & $1(7 \%)$ & 0.0009 \\
\hline Nodal & $5(24 \%)$ & $1(14 \%)$ & $4(29 \%)$ & 0.6244 \\
\hline Extranodal & $13(62 \%)$ & $3(43 \%)$ & $10(71 \%)$ & 0.3972 \\
\hline Both & $3(14 \%)$ & $3(43 \%)$ & $0(0 \%)$ & 0.0263 \\
\hline Stage, n (\%) & & & & 0.0256 \\
\hline Unifocal & $8(50 \%)$ & $0(0 \%)$ & $8(73 \%)$ & \\
\hline Multifocal & $8(50 \%)$ & $5(100 \%)$ & $3(27 \%)$ & \\
\hline Data not available & 5 & 2 & 3 & \\
\hline Follow-up (months) ${ }^{\mathrm{a}}$ & $84(7-352)$ & $74(7-352)$ & $94(16-154)$ & \\
\hline Outcome, n (\%) & & & & 1.0000 \\
\hline Clinical remission & $7(70 \%)$ & $4(80 \%)$ & $3(60 \%)$ & \\
\hline Persistent disease & $3(30 \%)$ & $1(20 \%)$ & $2(40 \%)$ & \\
\hline Data not available & 11 & 2 & 9 & \\
\hline
\end{tabular}

${ }^{\mathrm{a}}$ Number expressed as median (range).

LMNA-NTRK1 fusions were identified, the last two abnormalities leading to activation of related pathways, namely ALK, STAT3, and PI3K-AKT. ${ }^{21}$ Whereas our next-generation sequencing technology can detect insertions/deletions in addition to point mutations of the 134 genes included in the panel, we cannot detect gene fusions, and we cannot rule out mutations in other genes outside our panel. Nevertheless, we propose that Rosai-Dorfman disease is a clonal histiocytic disorder driven by genetic alterations, at least in mutated cases, similar to Langerhans cell histiocytosis and other non-Langerhans cell histiocytosis histiocytoses.

Clinically, Rosai-Dorfman disease is in general a self-limited disorder that allows conservative management. ${ }^{42}$ However, a small subset of patients experience refractory disease, locally aggressive lesions, or dissemination, denoting unfavorable prognosis. ${ }^{4,43-47}$ In complicated cases, radical resection, radiotherapy, or methotrexate combined with other chemotherapeutic agents, including 6-mercaptopurine or cladribine have been used, with different response rates. Standardized therapy for Rosai-Dorfman disease is yet to be established. ${ }^{42,47-49}$ Others have shown promising results using the RAF inhibitor, vemurafenib, as targeted therapy in patients with BRAF V600E-mutated histiocytoses, ${ }^{50-52}$ which has been followed by advances in additional targeted agents for patients with refractory histiocytoses. For example, in a study by Diamond et al. two patients with refractory Erdheim-Chester disease who harbored MAP2K1 mutations showed a clinical response to MEK inhibition with single-agent trametinib and cobimetinib, respectively. ${ }^{20}$ Similarly, a third patient with refractory Erdheim-Chester disease harboring mutated $A R A F$ showed rapid regression of the lesion after therapy with the tyrosine kinase inhibitor sorafenib. ${ }^{20}$ It seems likely that patients with non-selflimited histiocytoses with specific genetic abnormalities could potentially benefit from targeted therapy; however, more studies are required to sustain this idea.

In summary, the presence of mutually exclusive recurrent somatic KRAS and MAP2K1 mutations in $33 \%$ of archived Rosai-Dorfman disease specimens in this study further supports the idea that at least a subset of Rosai-Dorfman disease cases is clonal, expanding the list of histiocytic and non-histiocytic disorders harboring MAPK/ERK pathway mutations. We also provide evidence that MAP2K1 mutations induce constitutive activation of downstream ERK shown by positive p-ERK immunohistochemical staining. Finally, these results highlight the importance of comprehensive genomic analysis in Rosai-Dorfman disease, at least in patients with refractory or aggressive disease who may benefit from targeted therapy.

\section{Acknowledgments}

We thank Jawad Manekia and Mohammad Mohammad for technical assistance in the next-generation sequencing study.

\section{Disclosure/conflict of interest}

The authors declare no conflict of interest. 


\section{References}

1 Humble JG, Jayne WH, Pulvertaft RJ, et al. Biological interaction between lymphocytes and other cells. Br J Haematol 1956;2:283-294.

2 Rosai J, Dorfman RF. Sinus histiocytosis with massive lymphadenopathy. A newly recognized benign clinicopathological entity. Arch Pathol 1969;87:63-70.

3 Destombes P. [Adenitis with lipid excess, in children or young adults, seen in the Antilles and in Mali. (4 cases)]. Bull Soc Pathol Exot Filiales 1965;58:1169-1175.

4 Foucar E, Rosai J, Dorfman R. Sinus histiocytosis with massive lymphadenopathy (Rosai-Dorfman disease): review of the entity. Semin Diagn Pathol 1990;7: 19-73.

5 Foucar E, Rosai J, Dorfman RF. Sinus histiocytosis with massive lymphadenopathy. An analysis of 14 deaths occurring in a patient registry. Cancer 1984;54:1834-1840.

6 Foucar E, Rosai J, Dorfman RF et al. Immunologic abnormalities and their significance in sinus histiocytosis with massive lymphadenopathy. Am J Clin Pathol 1984;82:515-525.

7 Rosai J, Dorfman RF. Sinus histiocytosis with massive lymphadenopathy: a pseudolymphomatous benign disorder. Analysis of 34 cases. Cancer 1972;30:1174-1188.

8 Lauwers GY, Perez-Atayde A, Dorfman RF et al. The digestive system manifestations of Rosai-Dorfman disease (sinus histiocytosis with massive lymphadenopathy): review of 11 cases. Hum Pathol 2000;31:380-385.

9 Levine PH, Jahan N, Murari P et al. Detection of human herpesvirus 6 in tissues involved by sinus histiocytosis with massive lymphadenopathy (Rosai-Dorfman disease). J Infect Dis 1992;166:291-295.

10 Luppi M, Barozzi P, Garber R, et al. Expression of human herpesvirus- 6 antigens in benign and malignant lymphoproliferative diseases. Am J Pathol 1998;153: 815-823.

11 Mehraein Y, Wagner M, Remberger K, et al. Parvovirus B19 detected in Rosai-Dorfman disease in nodal and extranodal manifestations. J Clin Pathol 2006;59: 1320-1326.

12 Sarwal R, Tu E, Mendelblatt FI, et al. Atypical ocular presentations of Rosai-Dorfman disease. Ocul Immunol Inflamm 2008;16:9-15.

13 Tsang WY, Yip TT, Chan JK. The Rosai-Dorfman disease histiocytes are not infected by EpsteinBarr virus. Histopathol 1994;25:88-90.

14 Menon MP, Evbuomwan MO, Rosai J et al. A subset of Rosai-Dorfman disease cases show increased IgG4positive plasma cells: another red herring or a true association with IgG4-related disease?. Histopathology 2014;64:455-459.

15 Emile JF, Abla O, Fraitag S, et al. Revised classification of histiocytoses and neoplasms of the macrophagedendritic cell lineages. Blood 2016;127:2672-2681.

16 Badalian-Very G, Vergilio JA, Degar BA, et al. Recurrent BRAF mutations in Langerhans cell histiocytosis. Blood 2010;116:1919-1923.

17 Haroche J, Charlotte F, Arnaud L, et al. High prevalence of BRAF V600E mutations in Erdheim-Chester disease but not in other non-Langerhans cell histiocytoses. Blood 2012;120:2700-2703.

18 Roden AC, Hu X, Kip S, et al. BRAF V600E expression in Langerhans cell histiocytosis: clinical and immunohistochemical study on 25 pulmonary and 54 extrapulmonary cases. Am J Surg Pathol 2014;38: 548-551.
19 Sahm F, Capper D, Preusser M, et al. BRAFV600E mutant protein is expressed in cells of variable maturation in Langerhans cell histiocytosis. Blood 2012;120:e28-e34.

20 Emile JF, Diamond EL, Helias-Rodzewicz Z, et al. Recurrent RAS and PIK3CA mutations in ErdheimChester disease. Blood 2014;124:3016-3019.

21 Diamond EL, Durham BH, Haroche J, et al. Diverse and targetable kinase alterations drive histiocytic neoplasms. Cancer Discov 2016;6:154-165.

22 Heritier S, Saffroy R, Radosevic-Robin N, et al. Common cancer-associated PIK3CA activating mutations rarely occur in Langerhans cell histiocytosis. Blood 2015;125:2448-2449.

23 Chakraborty R, Burke TM, Hampton OA, et al. Alternative genetic mechanisms of BRAF activation in Langerhans cell histiocytosis. Blood 2016;128:2533-2537.

24 Alayed K, Medeiros LJ, Patel KP, et al. BRAF and MAP2K1 mutations in Langerhans cell histiocytosis: a study of 50 cases. Hum Pathol 2016;52:61-67.

25 Pina-Oviedo S, Medeiros LJ, Li S, et al. Langerhans cell histiocytosis associated with lymphoma: an incidental finding that is not associated with BRAF or MAP2K1 mutations. Mod Pathol 2017;30:734-744.

26 Kolch W. Coordinating ERK/MAPK signalling through scaffolds and inhibitors. Nat Rev Mol Cell Biol 2005;6: 827-837.

27 Montagut C, Settleman J. Targeting the RAF-MEK-ERK pathway in cancer therapy. Cancer Lett 2009;283: 125-134.

28 Robinson MJ, Cobb MH. Mitogen-activated protein kinase pathways. Curr Opin Cell Biol 1997;9:180-186.

29 Greaves WO, Verma S, Patel KP, et al. Frequency and spectrum of BRAF mutations in a retrospective, singleinstitution study of 1112 cases of melanoma. J Mol Diagn 2013;15:220-226.

30 Rahman MA, Salajegheh A, Smith RA et al. B-Raf mutation: a key player in molecular biology of cancer. Exp Mol Pathol 2013;95:336-342.

31 Zhang J, Wu G, Miller CP, et al. Whole-genome sequencing identifies genetic alterations in pediatric low-grade gliomas. Nat Genet 2013;45:602-612.

32 Falini B, Martelli MP, Tiacci E. BRAF V600E mutation in hairy cell leukemia: from bench to bedside. Blood 2016;128:1918-1927.

33 Waterfall JJ, Arons E, Walker RL, et al. High prevalence of MAP2K1 mutations in variant and IGHV4-34-expressing hairy-cell leukemias. Nat Genet 2014;46:8-10.

34 Zhang L, Singh RR, Patel KP, et al. BRAF kinase domain mutations are present in a subset of chronic myelomonocytic leukemia with wild-type RAS. Am J Hematol 2014;89:499-504.

35 Wang J, Liu Y, Li Z, et al. Endogenous oncogenic Nras mutation promotes aberrant GM-CSF signaling in granulocytic/monocytic precursors in a murine model of chronic myelomonocytic leukemia. Blood 2010;116: 5991-6002.

36 Berres ML, Lim KP, Peters T, et al. BRAF-V600E expression in precursor versus differentiated dendritic cells defines clinically distinct LCH risk groups. J Exp Med 2014;211:669-683.

37 Shanmugam V, Margolskee E, Kluk M et al.. RosaiDorfman disease harboring an activating KRAS K117N missense mutation. Head Neck Pathol 2016;10:394-399.

38 Go H, Jeon YK, Huh J, et al. Frequent detection of BRAF (V600E) mutations in histiocytic and dendritic cell neoplasms. Histopathology 2014;65:261-272. 
39 Chakraborty R, Hampton OA, Shen X, et al. Mutually exclusive recurrent somatic mutations in MAP2K1 and BRAF support a central role for ERK activation in LCH pathogenesis. Blood 2014;124:3007-3015.

40 Gatalica Z, Bilalovic N, Palazzo JP, et al. Disseminated histiocytoses biomarkers beyond BRAFV600E: frequent expression of PD-L1. Oncotarget 2015;6:19819-19825.

41 Zeng K, Ohshima K, Liu Y, et al. BRAFV600E and MAP2K1 mutations in Langerhans cell histiocytosis occur predominantly in children. Hematol Oncol 2016 [e-pub ahead of print].

42 Dalia S, Sagatys E, Sokol L et al.. Rosai-Dorfman disease: tumor biology, clinical features, pathology, and treatment. Cancer Control 2014;21:322-327.

43 Andriko JA, Morrison A, Colegial CH et al. RosaiDorfman disease isolated to the central nervous system: a report of 11 cases. Mod Pathol 2001;14:172-178.

44 Demicco EG, Rosenberg AE, Bjornsson J et al. Primary Rosai-Dorfman disease of bone: a clinicopathologic study of 15 cases. Am J Surg Pathol 2010;34:1324-1333.

45 Sandoval-Sus JD, Sandoval-Leon AC, Chapman JR, et al. Rosai-Dorfman disease of the central nervous system: report of 6 cases and review of the literature. Medicine (Baltimore) 2014;93:165-175.

46 O'Gallagher K, Dancy L, Sinha A et al. Rosai-Dorfman disease and the heart. Intractable Rare Dis Res 2016; $5: 1-5$.
47 Aouba A, Terrier B, Vasiliu V, et al. Dramatic clinical efficacy of cladribine in Rosai-Dorfman disease and evolution of the cytokine profile: towards a new therapeutic approach. Haematologica 2006;91: Ecr52.

48 Simko SJ, Tran HD, Jones J, et al. Clofarabine salvage therapy in refractory multifocal histiocytic disorders, including Langerhans cell histiocytosis, juvenile xanthogranuloma and Rosai-Dorfman disease. Pediatr Blood Cancer 2014;61:479-487.

49 Maia RC, de Meis E, Romano S et al. Rosai-Dorfman disease: a report of eight cases in a tertiary care center and a review of the literature. Braz J Med Biol Res 2015;48:6-12.

50 Haroche J, Cohen-Aubart F, Emile JF, et al. Dramatic efficacy of vemurafenib in both multisystemic and refractory Erdheim-Chester disease and Langerhans cell histiocytosis harboring the BRAF V600E mutation. Blood 2013;121:1495-1500.

51 Haroche J, Cohen-Aubart F, Emile JF, et al. Reproducible and sustained efficacy of targeted therapy with vemurafenib in patients with BRAF(V600E)-mutated Erdheim-Chester disease. J Clin Oncol 2015;33: 411-418.

52 Hyman DM, Puzanov I, Subbiah V, et al. Vemurafenib in multiple nonmelanoma cancers with BRAF V600 mutations. N Engl J Med 2015;373:726-736. 